\title{
DESENVOLVIMENTO E COOPERAÇÃO INTERNACIONAL
}

\author{
INTRODUÇÃO
}

\author{
Elsa Sousa Kraychete
}

Depois de ultrapassar mais de duas décadas como um assunto pouco visitado pelos debates acadêmicos e também pelas agendas governamentais, a temática do desenvolvimento reaparece entre pesquisadores de áreas como a economia, a sociologia e a ciência política, como também nos discursos e práticas de governo, como espaço de interesse de forma a reacender os debates sobre o tema. A noção de desenvolvimento, constituída como disciplina e adotada por governos dos países centrais do capitalismo, quando se referiam ao reordenamento do mundo, data da conjuntura pós-segunda Guerra Mundial e tem como primeiro berço a academia e think tanks americanas.

Teoricamente, a nova disciplina sustentase, em fundamentos keynesianos e neoclássicos. Dos primeiros fundamentos é tomada, em especial, a importância do Estado como garantidor da demanda efetiva, a partir de investimentos estatais e, posteriormente, numa leitura genero-

* Doutora em Administração. Professora do Instituto de Humanidades, Artes e Ciências Professor Milton Santos e o do Núcleo de Pós-Graduação em Administração da Universidade Federal da Bahia.

Rua Barão de Geremoabo, s/n. Ondina. Cep: 40170-240 Salvador - Bahia - Brasil. ekraychete@gmail.com sa da obra do economista inglês, como um dos fundamentos do welfare state. Da teoria neoclássica, será mantido o fundamento que orienta para o livre jogo das forças de mercado. A livre circulação de bens, de serviços e das finanças, em mercado autorregulador e autootimizador, não sujeito às restrições colocadas pelos estados nacionais, constitui-se, nessa perspectiva, em um dos mais importantes vetores do crescimento e do desenvolvimento das nações.

A teoria da sociológica da modernização, outro importante suporte para a conformação da nova disciplina, contribuiu para, a partir da noção dicotômica (tradicional e moderno), firmar o ideário do desenvolvimento, principalmente, quando a análise estava voltada para o entendimento da dinâmica socioeconômica dos países subdesenvolvidos. A oposição entre o tradicional e o moderno - predominância da produção agrícola sobre a indústria, como o exemplo mais citado - distinguia o estágio de desenvolvimento entre as nações. A teoria da modernização passou a ser referência teórica para entender a relação entre o a tradicional e o moderno no interior dos espaços nacionais, como também, para estabelecer comparações internacio- 
nais, entre os países classificados como moderno (desenvolvido) e atrasado (subdesenvolvido).

Os diagnósticos comparativos que passam a classificar as sociedades como desenvolvidas e subdesenvolvidas, por essa ótica, têm dois desdobramentos: colocar as economias capitalistas avançadas como horizonte - um espelho - a ser alcançado pelas sociedades dispostas a trilhar o caminho do progresso e, ao mesmo tempo, abrir espaço para a assistência técnica, ${ }^{1}$ como uma missão a ser desempenhada pelos países desenvolvidos nos países atrasados. Nessas bases, a terapia a ser indicada inclui a reformulação e ou criação de instituições capazes de implementar ações reformadoras. A técnica do planejamento - científica, neutra e, por suposto, isenta de disputas ideológicas - foi constituída em ferramenta que orientava para a resolução dos problemas que caracterizavam o subdesenvolvimento como resultado de eficiente “alocação de recursos”. O paradigma da objetividade anunciava-se como substituto da "escassez" (noção cara a certo modo de pensar a economia) para dar lugar à abundância decorrente da eficiência técnica. A eficiência, decorrente da modernização por meio da introdução de novas técnicas de produção e gestão, elevaria o excedente econômico em tal magnitude que tornava desnecessária a discussão sobre os modos de produzir e distribuir.

Repensar o mundo - entrecortado pelas disputas da guerra fria, pelo surgimento de novos países desmembrados do sistema colonial, como também de um grande número de nações mais antigas que almejavam modificar os termos de suas inserções internacionais - a partir de uma ordem -, contou com importante aparato institucional internacional e nacional. No âmbito nacional as sucessivas reformulações no aparelho de estado, mas que se estendem às organizações não estatais. As organizações intergovernamentais resultantes das concertações do final da Segunda Guerra se encarregaram do ordenamento internacional. Da ordem econômica se incumbi-

${ }^{1}$ Hoje denominada Cooperação Internacional para o Desenvolvimento. ram as organizações de Bretton Woods: Banco Mundial, o Fundo Monetário Internacional e o Acordo Geral de Tarifas (GATT), com atribuições, respectivamente, de fornecer créditos para o financiamento da infraestrutura, conceder empréstimos a países que enfrentavam dificuldades em equilibrar as suas contas externas e definição de normas para que o comércio entre as nações ocorresse sem os entraves que não fossem decorrentes das leis do mercado. A Organização das Nações Unidas, com seu grande número de agências (FAO, UNESCO, OMS, OIT...) também participa do ordenamento desenvolvimentista diagnosticando e recomendando intervenções na saúde, higiene, educação, alimentação, relações de trabalho, para citar alguns exemplos.

É também parte dessa ordem a constituição do Sistema de Cooperação Internacional para o Desenvolvimento que, iniciado com a ajuda com o Plano Marshall voltado para a reconstrução da Europa, teve prosseguimento com os programas de assistência técnica dirigidos para os países pobres, a exemplo da Aliança para o Progresso, dirigido para a América Latina. Parte das relações entre países do Norte e países do Sul, alcançou institucionalizar-se a partir da criação da Organização para a Cooperação e Desenvolvimento Econômico - OCDE.

A crise dos anos 1970 - expressa no desempenho dos indicadores macroeconômicos e, em seus aspectos mais estruturais, as modificações no modo de produzir, com a emergência de novas tecnologias, e nas relações de trabalho não deixa incólumes os paradigmas e o aparato institucional que conduziu o ordenamento desenvolvimentista desde o fim da Segunda Guerra. O momento passa a demandar novas estratégias e modo de regulação. O período que se abre a partir desse marco, testemunha sucessivos intentos de inovação institucional.

No decorrer das décadas de 70 e 80, já eram visíveis as mudanças no discurso das Organizações Internacionais sobre a temática do desenvolvimento. Num primeiro movimento, essas mudanças se manifestaram na crítica ao 
desenvolvimentismo guiada por concepções anteriores, em especial, sobre a presença do Estado na economia, e pela reafirmação do pensamento neoclássico, expresso na competição baseada no livre-comércio, na estabilização dos preços e na desregulamentação dos mercados.

As medidas voltadas para a retomada do crescimento econômico se fazem acompanhar da eleição da pobreza como a temática mais importante dentre as que irão constituir a nova agenda em prol do desenvolvimento. Sob o argumento de que o crescimento econômico não conduziria ao bem-estar das grandes maiorias das populações dos países subdesenvolvidos, aparecem os primeiros delineamentos de políticas de minoração da pobreza, inspiradas na ideia de justiça como equidade. Predomina no debate os princípios do liberalismo econômico e político, que vai apresentar-se com renovações na direção da redefinição do trato da questão social. O discurso das Organizações Internacionais é perpassado pelos princípios liberais dos direitos, da liberdade e da justiça.

A concepção liberal que passa a comandar as análises das instituições da cooperação internacional considera a existência das necessidades básicas a serem prioritariamente atendidas e que tais necessidades podem ser medidas, definidas e classificadas. Daí a importância atribuída às técnicas de mensuração da pobreza que visam definir carências em itens tais como, alimentação, saúde, educação e habitação. A partir do nível de carências, serão definidas políticas orientadas para grupos específicos. Essa concepção, Organizações da Cooperação Internacional envidam esforços em detectar os pobres por meio de tecnologias que não só dêm conta do número destes, como distinga entre eles os mais pobres entre os pobres. Esse procedimento orienta a focalização das políticas, com os mais pobres devendo ser atendidos por políticas de caráter compensatório e os demais por políticas orientadas pelo mercado. Enquanto as políticas compensatórias devem agir em favor do fortalecimento das capacidades individuais, com o propósito de fortalecer os indivíduos, de forma a que possam competir em igualdade de condições com outros grupos, as políticas orientadas para o grupo dos pobres, sustentam-se nos valores expressos no empreendedorismo competitivo.

Também o modo de regulação passa por alterações significativas. $\mathrm{O}$ ajuste institucional sob a ideia de boa governança propõe a adequação das instituições às exigências da conjuntura econômica e política. A boa governança deve garantir, segundo as diretrizes do Banco Mundial, o funcionamento de uma economia de mercado em que os direitos de propriedade sejam estáveis, os contratos sejam cumpridos, haja transparência das práticas institucionais. O Estado e o mercado são levados a praticar ações com vista ao estabelecimento de parcerias entre si, como também atuem de forma capaz de estabelecer pactos com a sociedade civil. Esse enfoque orienta na direção de mudanças internas nas instituições e de emergência de novos arranjos interinstitucionais. Nos desdobramentos para a formulação de políticas, a ideia é que os mercados e os governos atuem como parceiros e, juntos, promovam o aprimoramento institucional para implementar reformas que venham conceber e conduzir novos modos de regulação e também estabelecer os limites decorrentes da explicitação dos conflitos.

A Cooperação Internacional para o Desenvolvimento também passa por reorientações. A realização de um conjunto de conferencias, reuniões de cúpula intergovernamentais, fóruns, orientadas pelas noções de eficiência e eficácia buscam sintonizar a ajuda oficial para o desenvolvimento com as metas definidas nos Objetivos de Desenvolvimento do Milênio. A reconfiguração geopolítica com a emergência de países como Brasil, México, Índia, China, Turquia ou África do Sul, também inaugura outra forma de cooperação internacional para o desenvolvimento, a cooperação entre países do Sul.

O conjunto de artigos que compõem este dossiê trata da problemática do desenvolvimento e do sistema de cooperação internacional que o acompanha. O primeiro artigo, Paradigma do desenvolvimento: controvérsias e inflexões con- 
temporâneas, de Anete L. B. Ivo, recupera o debate que acompanha a trajetória da ideia de desenvolvimento, buscando, "[...] oferecer um fio condutor sobre os sentidos do desenvolvimento brasileiro." Para isso, recupera o debate , primeiro, a trajetória das primeiras décadas do século $\mathrm{XX}$, quando a questão central girava em torno dos dilemas entre tradição e modernidade, passa pelas principais teses do nacionaldesenvolvimentismo, caraterísticas do debate entre os anos 50 e 70, e alcança as inflexões do paradigma do desenvolvimento, a partir dos anos 1980, em contexto de democratização e reajuste estrutural. Perpassa toda a análise a presença do conflito, da integração social e das classes.

Carlos Milani, no artigo Aprendendo com a história: críticas à experiência da Cooperação Norte-Sul e atuais desafios à Cooperação Sul-Sul, a partir da hipótese “... de que a diferenciação entre CNS e CSS é fundamentalmente empírica, devendo, no entanto, ser pensada à luz do legado do ativismo multilateral de alguns países e do novo papel econômico e político que desempenham no cenário internacional”, conduz o argumento alertando para os riscos que correm os países do Sul, hoje doadores, de reproduzir o modelo de cooperação Norte-Sul, objeto de críticas.

$\mathrm{O}$ artigo Transformações globais, potências emergentes e cooperação Sul-Sul: desafios para a cooperação europeia, de Bruno Ayllón Pino, analisa a mudança na distribuição de poder e geração de riquezas em nível mundial, que redefinem o sistema de cooperação e desafiam os países do norte, em particular os que compõem a União Europeia, a repensar as suas modalidades de cooperar. Recomenda, nessa direção, a adoção de formas complementares de cooperação que contemplem o intercâmbio de conhecimentos e difusão de experiências exitosas. Considera que a cooperação Sul-Sul, promovida pelas potências emergentes segue aumentando presença no cenário da cooperação, legitimada pelas recentes e exitosas experiências de redução da pobreza.

Analisar o espaço sociorganizativo que envolve o mercado, o Estado e a sociedade civil nos arranjos institucionais propostos por organizações internacionais como espaço de busca de consenso para a condução da agenda de desenvolvimento é o objetivo do artigo O lugar das organizações não governamentais no entrecruzamento entre as noções de desenvolvimento e cooperação internacional, de Elsa Sousa Kraychete. A posição atribuída às organizações organizações não governamentais e as empresas, passam a ser consideradas como importantes nas concertações que visam a formulação e implementação de políticas públicas é questionada a partir da visão que a noção de direitos pode estar sendo substituída por ações voluntárias e temporárias.

Daniel Maurício de Aragão, no artigo O controle global da solidariedade: transnacionalização e privatização na adaptação estratégica de ONGs britânicas no Brasil analisa a mudança de estratégia de ONGs britânicas de solidariedade internacional, com histórica presença no Brasil como doadoras de recursos, vêm identificando o Brasil como um espaço potencial para a captação de recursos, especialmente em parceria com o setor privado. Com base nos exemplos da OXFAM e da Save the Children, conclui que o novo cenário da cooperação internacional não governamental marcado por processos associados de transnacionalização e privatização deixa marcas no perfil e na agenda tais organizações.

(Recebido para publicação em 27 de julho de 2012) (Aceito em 02 de agosto de 2012

Elsa Sousa Kraychete - Economista. Doutora em Administração. Professora do Instituto de Humanidades, Artes e Ciências Professor Milton Santos e do Núcleo de Pós-Graduação em Administração - NPGa, da Universidade Federal da Bahia - UFBA. Coordena o Laboratório de Análise Política Mundial - LABMUNDO/ Antena Salvador. Membro da Câmara de Assessoramento de Ciências Humanas da FAPESB. Editora científica do Caderno CRH. Trabalha centralmente com as seguintes temáticas: desenvolvimento, organizações internacionais e cooperação internacional para o desenvolvimento, organizações não governamentais. 